\section{Dental or dentist?}

\author{
Stephen Hancocks OBE \\ Editor-in-Chief
}

It hardly seems possible that it is now ten years since, some of us at least, were looking forward to the dawn of the new millennium, fretting about Y2K viruses (remember them?), predicting that aircraft would drop from the sky at the stroke of midnight and betting that not even Tony Blair could get the Dome finished in time.

Yet here we are poised on the brink of the second decade of the brave new century, wondering what will befall us in the 520 weeks ahead. Predictions are always very dangerous. Who, for example, could have foreseen the changes to the profession since 31/12/99? Difficult to believe now that in those heady far-off days we had never heard of the initials DCP (Dental Care Professionals) - at that time the designation was quite the other way around as PCD - Professionals Complementary to Dentistry. Nor was the other, now common, combination of those three letters, CPD (Continuing Professional Development) in regular usage. And as for UDAs...

However, there is predicting the future and there is deciding to help shape it. Leaders of the BDA, in anticipating local commissioning and increase in private practice have ensured that the quality, breadth and depth of advice offered to members is second to none. This has ensured that the level of individual contact with members has increased dramatically, so that in any given quarter of the year nearly one third of the 23,000 plus membership contacts the Association for advice; providing an ever improving service and adding value to membership.

\section{HIGH ESTEEM BY DCPS}

What may come as something of a revelation is that the Association is also held in high esteem by DCPs. Before we relaunched Vital, the BDA's quarterly publication for DCPs, we undertook market research, part of which involved focus groups. To our pleasant surprise, members of the various DCP groups cited the BDA as being excellent for its advice, its publications, as the first port of call for information and the primary source of dental knowledge. How were they able to access the content and to know this? The answer was through 'their dentist's' membership. The story continued in hearing that hygienists and therapists ache to be able to read and access the $B D J$ but have to borrow their dentist's copy because they themselves are unable to subscribe or receive it through BDA membership.

Is it not therefore time for us to begin to seriously discuss how and when we are to bring all of the team members together
Send your comments to the

Editor-in-Chief,

British Dental Journal

64 Wimpole Street,

London

W1G 8YS

Email bdj@bda.org within a collaborative structure supported by the strength of the BDA? Whatever form it takes it must respect the autonomy of the other professional societies and associations. It is important that each of these keep their separate identities for the furtherance of their members' interests and to advance and develop their particular branch of the profession. But in the same way that the different 'crafts' are accommodated within the BDA and that BDA members also belong to the many and varied specialist societies, so too surely can equivalent methods be found and links forged.

The BDA is already demonstrating this by actively participating in the All Party Group with the BDTA and others, being inclusive of all team members and their organisations in the annual Honours and Awards Dinner, as well as providing various educational opportunities for DCPs, who are also now attending BDA Branch and Section meetings in significant numbers. The GDC Registers currently consist of over 55,000 DCPs and 35,000 dentists. A coalition which potentially counted 90,000 members is far more robust than a profession divided by disciplines and factions.

The details of how this might be achieved are for others to discuss, hone, model and agree but I earnestly suggest that it must now be placed on the agenda and marked urgent. Other organisations have taken this step and show no signs of regret, reversion or of plunging into hideous decline as a result of embracing the innovation. Quite the opposite. It must be time for the BDA to debate and advance this important area, or else how can we be even remotely regarded as justifying the mantle of leading the profession? Are we to allow ourselves to be consigned to history as the dental association that only encompasses dentists, despite the fact that DCPs can now own and run dental practices and employ dentists? Or should we instead grow in the coming ten years and prove that we are as grownup and forward-looking in collectively leading our profession as we are individually in leading and moulding our teams? The choice is ours but the result will inform history's verdict.

I doubt I will be reflecting on this editorial page at this point in 2019 but my personal and sincere hope is that even if I am only writing my personal diary, sipping my bedtime hot chocolate and gently parting the curtains to see the fireworks exploding for the third decade, I will be able to note with satisfaction that the BDA will have proudly earned the Dental in its name and not be only Dentist in its membership.

Happy New Year and Healthy New Decade.

DOI: 10.1038/sj.bdj.2009.1138 